\title{
VIVALDI ANTIPODAL ANTENNA WITH HIGH GAIN AND REDUCED SIDE LOBE LEVEL USING SLOT EDGE WITH NEW NEOGOTHIC FRACTAL BY CANTOR WITH APPLICATION IN MEDICAL IMAGES FOR TUMOR DETECTION
} Auzuir R. De Alexandria ${ }^{5}$, João F. Justo ${ }^{6}$, Marcelo B. Perotoni ${ }^{7}$, Nurhayati ${ }^{8}$, and Ingrid C. Nogueira ${ }^{9}$

\author{
1,2,3,4,5,6,7,8,9 Maxwell Laboratory of Microwave and Applied Electromagnetism at the Federal Institute of São Paulo, \\ Brazil \\ ${ }^{4}$ Department of Electrical Engineering, Federal University of Campina Grande, Brazil \\ ${ }^{5}$ Federal Institute of Ceará, Brazil \\ ${ }^{6}$ Electronic Systems Engineering Department, Polytechnic School of the University of São Paulo, Brazil \\ ${ }^{7}$ Federal University of ABC, Brazil \\ ${ }^{8}$ Departement of Electrical Engineering, Universitas Negeri Surabaya in Indonesia \\ ${ }^{9}$ Christus University Center, Brazil \\ ${ }^{1}$ raimundo@labmax.org; ${ }^{2}$ amanicoba@ifsp.edu.br; ${ }^{3}$ anmendes@ifsp.edu.br; \\ 4alexandreserres@dee.ufcg.edu.br; 5 auzuir@labmax.org; 6jjusto@lme.usp.br; \\ ${ }^{7}$ marcelo.perotoni@labmax.org; ${ }^{8}$ nurhayati@unesa.ac.id; ${ }^{9}$ ingridcnfisio@gmail.com
}

\begin{abstract}
This article addresses the study of the Vivaldi Antipodal Antenna (AVA) seeking to improve the gain, decrease the Side Lobe Level (SLL) and the squint, to make the antenna more directive and obtain a more stable radiation pattern. Its intended application lies in the generation of biological microwave imaging to detect brain tumors. With this objective, the Fractal Slot Edge (FSE) technique was applied with a new fractal developed and based on the Cantor set. The application of this fractal, called Cantor Neogothic Fractal (CNG), formed different-sized cavities resulting, in this work, in three antennas that were analyzed through numerical computational simulation together with AVA. The antennas, called CNG9-FSE-AVA, CNG18-FSE-AVA, and CNG27-FSE-AVA, in which 9, 18, and 27 define the maximum height that the fractal reached in each antenna, have areas equal to $354.66 \mathrm{~mm}^{2}, 709.33 \mathrm{~mm}^{2}$ and $1064 \mathrm{~mm}^{2}$, respectively. All antennas achieved the goal, however, CNG27-FSE-AVA presented the best results at $2 \mathrm{GHz}$, with a gain of $7.84 \mathrm{dBi}$, SLL $-19.80 \mathrm{~dB}$, and squint of $\mathbf{- 0 . 1 0}$ degree. Additionally, it was proved that the antenna is suitable to generate a near field microwave imaging of tumors in a brain model.
\end{abstract}

Keywords: Ultrawide band (UWB), fractal antennas, slot edge, Vivaldi Antenna.

\section{INTRODUCTION}

In order to intermediate the energy transmission between a waveguide and the free space, it is necessary to use a device capable of radiating and transmitting electromagnetic waves [1], that is, an antenna. There are several types of antennas, such as patch, horn, Yagi-Uda, and the Antipodal Vivaldi Antenna (AVA), on which this article is based. The choice of AVA is due to its low cost, lightness, easy integration with planar structures and compact dimensions [1], [2], [3], [4], besides its broadband [3], [5], high efficiency and gain [5] and, for being directive [6], an ideal feature for medical images [6]. In addition, it also favors its wide applicability in ultra-wideband (UWB) systems, such as: spacecraft [1], satellites [1], [2], biological images for medical purposes [7], [8], radars [2], [3], [7], telescopes [2], remote sensing [2], [4], images through walls [5], and, for being directive [6]. Moreover, it also favors its wide applicability in ultra-wideband (UWB) systems, such as: spacecraft [1], satellites [1], [2], biological imaging for medical purposes [7], [8], radars [2], [3], [7], telescopes [2], remote sensing [2], [4], images through walls [5], 5G communication [9], microbiological sterilization [10] and unmanned aerial vehicles [1].

In order to improve directivity, the Side Lobe Level (SLL), gain, and squint, over time several techniques have been studied and applied in AVA, some of which are 
presented below: (a) the Balanced AVA (BAVA) and BAVA with a director [7], despite reducing the crosspolarization [3] and improving the gain [7], presents constructive complexity and higher cost than AVA, because it uses several layers of substrates; (b) the elliptical director in AVA [2] works as a wave guide directing energy to the center of the main radiator of the antenna [7] and presents an improvement in directivity [2]; (c) the use of dielectric lenses, metamaterials [2], [9] and polylactic acid (PLA) [10] results in improved gain and decrease of SLL, but the physical dimensions of the antenna were left uncharacterized [6], preventing, for example, the application of this technique in a precision missile by losing the compact and size [1].

Despite presenting several positive characteristics for UWB systems, an AVA has some deficiencies caused by its long side edges that impair directivity and generate high SLL affecting, consequently, the antenna radiation stability [2]. To mitigate these limitations, this work proposes the design of an AVA applying the FSE technique using a new fractal, which was here called Cantor Neogothic (CNG), such fractal was developed for this article based on the Cantor set and aims to increase the gain, decrease the SLL and squint and observe how much the area of the notches on the lateral edges influences the antenna frequency.

Another purpose of this work is to apply the proposed antenna on the generation of near-field microwave images to detect brain tumors, assisting in the medical diagnosis of cancer. This goal can be achieved because of the different electrical properties of healthy and malignant biological tissues [11], [12], [13].

This article is oriented as follows: Section II is the development of the new CNG fractal and the AVA and CNG-FSE-AVA antennas; Section III discusses the results obtained through numerical computational simulations, Section IV demonstrates the signal processing and the tumor and brain images and their respective dimensions and, finally, Section $\mathrm{V}$ presents the conclusion.

\section{ANTENNAS AND FraCtAL DEVELOPMENT}

\section{a. Antennas}

The AVA used in the simulation in this article is based on the optimized antenna reported in [10].

The numerical model of the antenna substrate for simulation purposes was FR4 with a dielectric constant of 4.3 and a thickness of $1.6 \mathrm{~mm}$.

The substrate thickness was taken into consideration in the design, as there is a sensitivity to high frequencies and cause changes in the phases of electromagnetic waves in the main radiator causing distortions [2].
To obtain the exponential function of the main radiator curve $f_{1}(\mathrm{z})$ and $f_{2}(\mathrm{z})$ equation (1) was used.

$$
f(\mathrm{z})=\mathrm{c}_{1} \mathrm{e}^{\mathrm{Rz}}+\mathrm{c}_{2}
$$

Where $\mathrm{R}$ is the exponential opening coefficient with values between 0.038 and 0.055 .

On the other hand, $c_{1}$ and $c_{2}$ are the curves given by equations (2) and (3), respectively.

$$
\begin{aligned}
& \mathrm{c}_{1}=\frac{\mathrm{s}_{2}-\mathrm{s}_{1}}{\mathrm{e}^{\mathrm{Rz} \mathrm{z}_{2}}-\mathrm{e}^{\mathrm{Rz}} \mathrm{Rz}_{1}} \\
& \mathrm{c}_{2}=\frac{\mathrm{s}_{2} \mathrm{e}^{\mathrm{Rz} \mathrm{z}_{2}}-\mathrm{s}_{1} \mathrm{e}^{\mathrm{Rz}}}{\mathrm{e}^{\mathrm{Rz} \mathrm{z}_{2}}-\mathrm{e}^{\mathrm{Rz_{1 }}}}
\end{aligned}
$$

Fig. 1 presents the conventional AVA antennas (Fig. 1 (a)) and the other proposals, called CNG9-FSE-AVA (Fig. 1 (b)), CNG18-FSE-AVA (Fig. 1 (c)), and CNG27-FSEAVA (Fig. 2). 1 (d)), which have the same Neogothic Cantor Fractal but with different areas of the lateral cavities, where the numerical numerals denominate the maximum length in millimeters of the lateral cavity carved by the fractal, in CNG9-FSE-AVA is $9 \mathrm{~mm}$, in CNG18FSE-AVA $18 \mathrm{~mm}$, and in CNG27-FSE-AVA $27 \mathrm{~mm}$. The dimensions and parameters are shown in Table I.

TABLE I

DiMENSIONS AND PARAMETERS OF AVA, CNG9-FSE-AVA, CNG18FSE-AVA, AND CNG27-FSE-AVA.

\begin{tabular}{cccccc}
\hline \multicolumn{5}{c}{ Dimension parameters [mm] } \\
\hline $\mathrm{a}$ & 53.50 & $\mathrm{~b}$ & 58.36 & $\mathrm{c}$ & 55.00 \\
$\mathrm{~d}$ & 150.00 & $\mathrm{e}$ & 18.10 & $\mathrm{f}$ & 1.00 \\
$\mathrm{~g}$ & 27.00 & $\mathrm{r}$ & 20.00 & $\mathrm{w}_{1}$ & 150.00 \\
$\mathrm{w}_{2}$ & 113.71 & & & &
\end{tabular}

The $\mathrm{a}, \mathrm{b}, \mathrm{c}, \mathrm{d}, \mathrm{e}, \mathrm{r}, \mathrm{w}_{1}$, and $\mathrm{w}_{2}$ parameters are identical for AVA and all CNG-FSE-AVA designs presented in this work. Parameters $\mathrm{f}$ and $\mathrm{g}$ are identical for all CNG-FSE-AVA antennas with fractals.
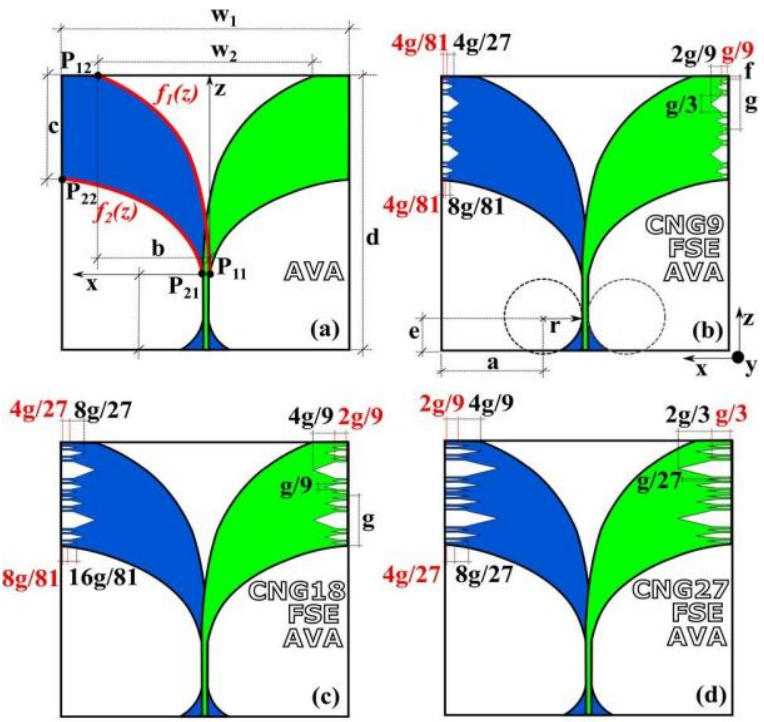

Fig. 1. Parameter and Dimensions: (a) AVA, (b) CNG9-FSE-AVA, (c) CNG18-FSE-AVA, (d) CNG27-FSE-AVA. 
All the antennas presented have dimensions $160 \times 160$ $\mathrm{x} 1.6 \mathrm{~mm}^{3}$, however they can be reduced using substrates with larger dielectric constants [1], [8], but, on the other hand, it will cause a reduction in bandwidth [1].

\section{b. Fractal}

The term fractal was defined by Mandelbrot as geometries that have self-similarity and self-affinity [1], [11]. The use of fractals in antennas is due to their ability to reduce SLL [11], to make the antennas more compact due to their ability to occupy small spaces, multiband, increase the bandwidth [11], [12], in addition to maintaining the radiation patterns due to their characteristic of self-similarity [12]. Due to these characteristics and based on the fractal of the city of Cantor, in this work a new fractal called Neogothic of Cantor was developed, this denomination arises from the similarities observed between the pointed geometry of the fractal and the characteristics of the towers of the Neogothic architecture. The CNG, with three iterations, is applied on the lateral edges of the AVA causing cavities.

Fig. 2 shows the CNG fractal with its first three iterations from a generator element that is a straight line. The developed fractal has a ratio of $1 / 3$ and its Hausdorff dimension is 0.63 , therefore equal to that of the Cantor set. The iterations occur as follows: (a) the generating element, in the case of a straight line, is divided into three equal parts; (b) the central part is extracted; (c) adds the triangular pointed geometric figure to the center in which the height of its base (h), which represents a rectangular figure, is $1 / 3$ of the maximum height $(\mathrm{H})$ of the figure, this maximum height is not fixed being defined by the user, in this work were used three different $\mathrm{H}$ which are $1 / 3,2 / 3$ and $3 / 3$ of the generating element of $27 \mathrm{~mm}$ in length; (d) after these three steps return to step (a) but the maximum height of the towers in the next iterations are $2 / 3$ of the height of the previous iteration.

\section{ITERATIONS}

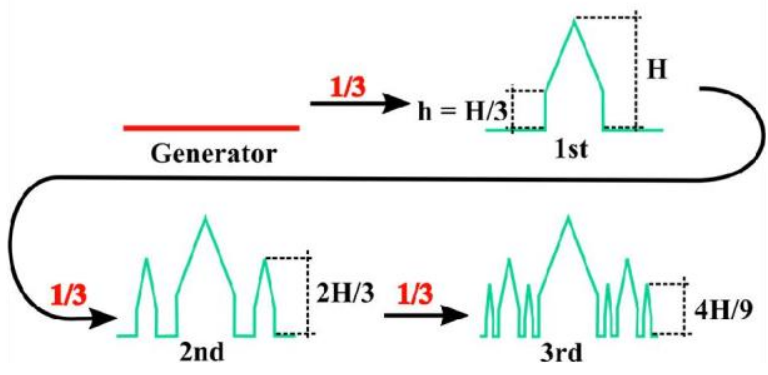

Fig. 2. Iterations new Neo-Gothic Fractal by Cantor.

\section{III.SIMULATION RESULTS}

Fig. 3 illustrates the simulated reflection coefficients of the four antennas, especially the CNG27-FSE-AVA which obtained a resonance frequency of $2.01 \mathrm{GHz}$ being lower than the others, this occurs because CNG27-FSEAVA presents more extensive curves [12] than the others and their cavities have an area of $532 \mathrm{~mm}^{2}$ on each side edge of the AVA. Considering that the CNG9-FSE-AVA has an area of $180.28 \mathrm{~mm}^{2}$ on each edge, and the CNG18FSE-AVA, has $354.66 \mathrm{~mm}^{2}$ of notched area on each edge, the CNG27-FSE-AVA, is the one with the largest cavities.

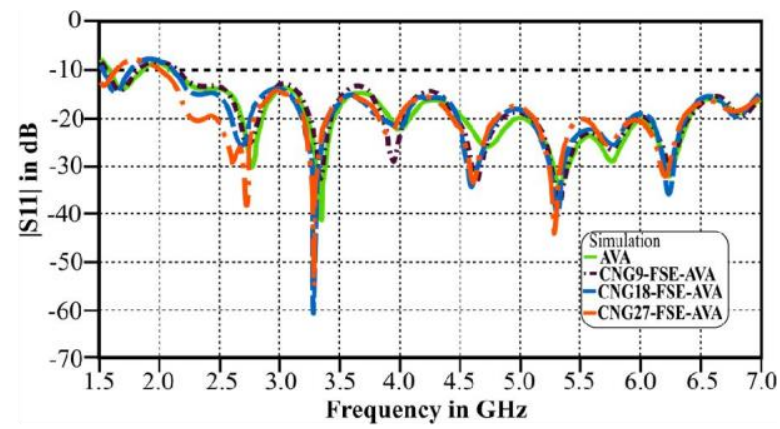

Fig. 3. Parameter S11 of AVA, CNG9-FSE-AVA, CNG18-FSE-AVA and CNG27-FSE-AVA.

Fig. 4 shows the computed frequency variation of the gain. It is possible to see that the CNG9-FSE-AVA presents its best gain at $4 \mathrm{GHz}$ with $9.28 \mathrm{dBi}$, it can be noticed in the frequencies above $5.5 \mathrm{GHz}$ the gain was practically constant in the analyzed range. The CNG18FSE-AVA showed a peak gain of $9.78 \mathrm{dBi}$ at $7 \mathrm{GHz}$, thus being better than the other units, while the CNG27-FSEAVA showed $9.75 \mathrm{dBi}$ gain at $5.5 \mathrm{GHz}$. All the proposed antennas had larger gains than a conventional AVA.

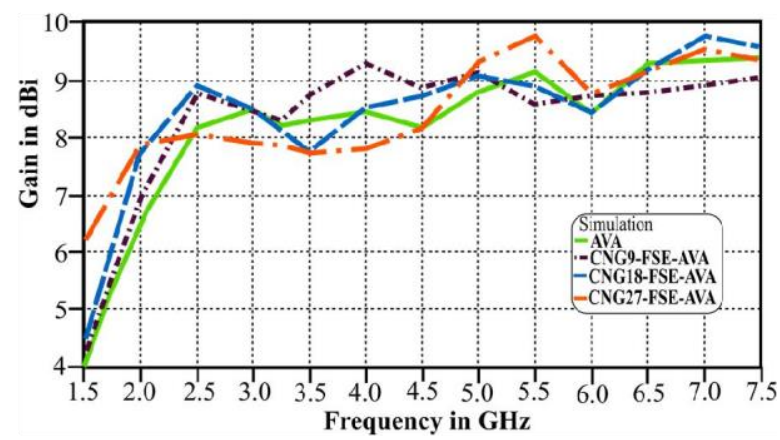

Fig. 4. Gain of AVA, CNG9-FSE-AVA, CNG18-FSE-AVA, and CNG27-FSE-AVA.

Fig. 5 shows the $2 \mathrm{GHz}$ radiation pattern from which the gain, SLL, squint, and angular width of the electromagnetic radiation from the antennas is extracted. The results obtained in Fig. 5 are presented in Table II, as well as the total area of the lateral cavities.

It was possible to observe from the results extracted from Fig. 5, that the larger the airway carved on the lateral edges of the antenna the greater the gain, the lower the 
strabismus and the greater the reduction of the SLL, however, with the increase of the cavity areas there was an increase in the angular width of the radiation. Among the results, the CNG27-FSE-AVA antenna, which has larger side cavities compared to the other two proposed antennas, with considerable reductions in the SLL of $-8.60 \mathrm{~dB}$, practically extinguishing the squint, occurring a reduction of 2.70 degrees, and increasing the gain by $1.36 \mathrm{dBi}$ compared to AVA, which makes the CNG27-FSE-AVA an antenna of the Palm Tree class by simultaneously reducing the SLL and increasing the gain [6], as well as the CNG9-FSE-AVA, and CNG18-FSE-AVA.

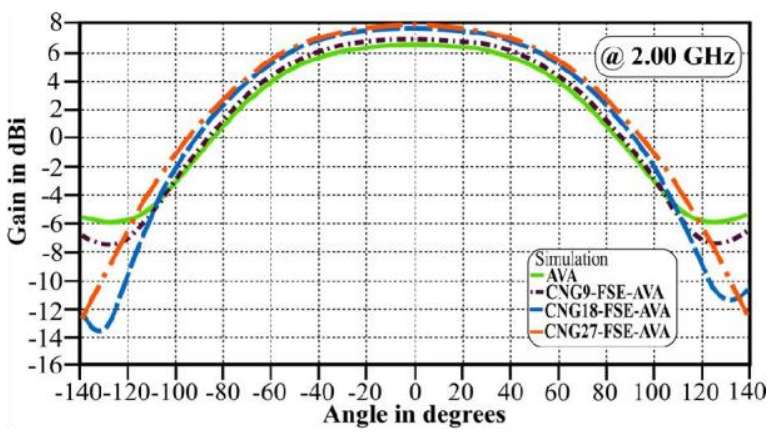

Fig. 5. 2D Radiation patterns in $2 \mathrm{GHz}$ of AVA, CNG9-FSE-AVA, CNG18-FSE-AVA, and CNG27-FSE-AVA.

Fig. 6 also illustrates a 2D radiation pattern, but at 4 GHz. When analyzing the results, shown in Table II, it was possible to observe that, at this frequency, the smaller the notched area of the lateral cavities for the Neogothic fractal the greater the gain and reduction of SLL, as is the case of the CNG9-FSE-AVA, which has a smaller notched area at the edges of the AVA by the CNG.

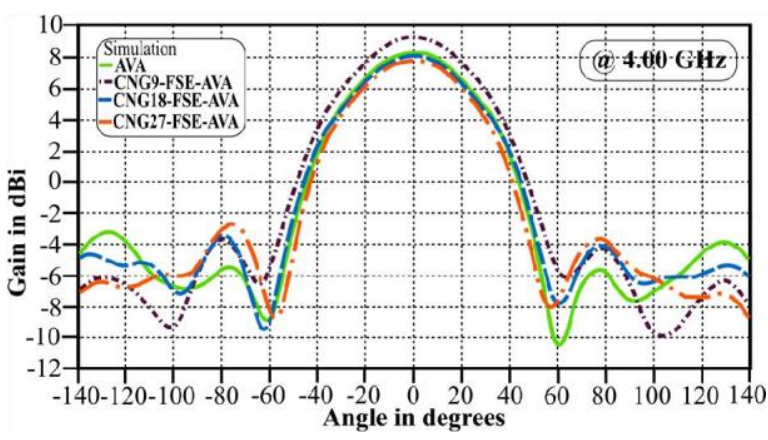

Fig. 6. 2D Radiation patterns in $4 \mathrm{GHz}$ of AVA, CNG9-FSE-AVA, CNG18-FSE-AVA, and CNG27-FSE-AVA.

The results shown in Table II show that the areas carved in the cavities by CNG behave differently with respect to frequencies, i.e., at a lower frequency the greater the area carved on the side edges the better the antenna performance and at a higher frequency the smaller the area the better the performance.
TABLE II

COMPARISON OF THE PRoPoSEd AVA, CNG9-FSE-AVA, CNG18-FSE-

\begin{tabular}{|c|c|c|c|c|}
\hline \multicolumn{5}{|c|}{ At $2.00 \mathrm{GHz}$} \\
\hline $\begin{array}{l}\text { Parameters } \\
\text { Results }\end{array}$ & AVA & $\begin{array}{c}\text { CNG9- } \\
\text { FSE- } \\
\text { AVA } \\
\end{array}$ & $\begin{array}{c}\text { CNG18- } \\
\text { FSE- } \\
\text { AVA } \\
\end{array}$ & $\begin{array}{c}\text { CNG27- } \\
\text { FSE- } \\
\text { AVA } \\
\end{array}$ \\
\hline Gain in $d B i$ & 6.48 & 6.87 & 7.71 & 7.84 \\
\hline$S L L$ in $d B$ & -11.20 & -11.90 & -15.00 & -19.80 \\
\hline $\begin{array}{c}\text { Squint in } \\
\text { degrees }\end{array}$ & 2.80 & 2.90 & -0.10 & -0.10 \\
\hline $\begin{array}{c}\text { Angular Width } \\
\text { in degrees }\end{array}$ & 127.40 & 127.50 & 128.40 & 131.10 \\
\hline \multicolumn{5}{|c|}{ At $4.00 \mathrm{GHz}$} \\
\hline Gain in $d B i$ & 8.26 & 9.23 & 8.10 & 7.79 \\
\hline$S L L$ in $d B$ & -11.50 & -12.90 & -11.50 & -10.60 \\
\hline $\begin{array}{c}\text { Squint in } \\
\text { degrees }\end{array}$ & 0.10 & 0.10 & 0.10 & -0.20 \\
\hline $\begin{array}{c}\text { Angular Width } \\
\text { in degrees }\end{array}$ & 55.60 & 56.40 & 56.90 & 54.20 \\
\hline $\begin{array}{l}\text { Area slot edge } \\
\text { in } \mathrm{mm}^{2}\end{array}$ & 0 & 354.66 & 709.33 & 1064 \\
\hline
\end{tabular}

\section{BRAIN AND IMAGE SYNTHESIZED}

\section{a. Brain and Tumor}

The use of microwaves has advantages in medical imaging systems due to their non-ionizing radiation [13], [16], making them safer [17], in addition to their low cost of implementation [17].

Healthy tissues have a dielectric constant $\varepsilon$ lower than malignant tumors [11], this is because there is a concentration of sodium in the tumor cells, causing fluid retention [11]. The dielectric properties of malignant tissues change at each stage [11] of the tumor. As the microwaves interact with the tissues due to the polarization of the molecules, they generate reflections that are captured by the antenna [11], the signals received by the antenna are backscattered due to the different $\varepsilon$ [17]. However, the tumors, due to their high $\varepsilon$, reflect more intensely than healthy tissues [16].

For simulation purposes, a computer numerical model of a human brain, with $\varepsilon$ of 8.6, and of the tumor, with $\varepsilon$ of 74 , was used. Although the head has other tissues such as skin, fat, skull, cerebral spinal fluid (CSF), mass (gray and white) [13] which, therefore, have different dielectric properties, this work used only the properties of the brain mass. The dimensions of the brain model are shown in Fig. 7. To model the tumor, the geometry of a sphere with a diameter of $37 \mathrm{~mm}$ located on the front of the brain was adopted. 


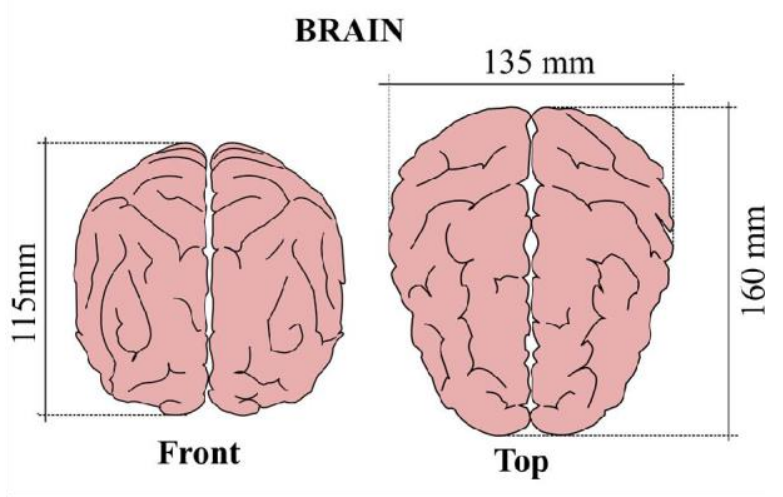

Fig. 7. Dimensions model brain.

\section{b. Signal Processing and Image}

The generation of nearfield images by microwaves in this work was carried out in two stages. The first is the transmission of electromagnetic waves and the reception of signals by CNG27-FSE-AVA. In the second, there is the acquisition, by the time domain reflectometer (TDR), and the data treatment using algorithms developed in Scilab 6.0.1 for image generation.

The algorithm was based on the work reported in [8] but is differentiated by acquiring data in the time domain by TDR, using the Shannon energy function [18] and having one step less than the five in [8].

In the first stage, the CNG27-FSE-AVA traversed the $\mathrm{x}$-axis $(150$ to $-150 \mathrm{~mm})$ in 21 positions at $20 \mathrm{~mm}$ from the front of the brain model. There is transmission of flat electromagnetic waves and reception of reflected signals. From these signals, the data are acquired through the TDR that obtains the line impedance correspondence, helping in the analysis of the reflections caused by the materials that interacted with the electromagnetic waves. The simulations were performed in the brain model with and without a tumor.

From these TDR data, in the form of a matrix of 21 columns per 1001 lines, the signal is processed in three stages presented in the flowchart of Fig. 8.

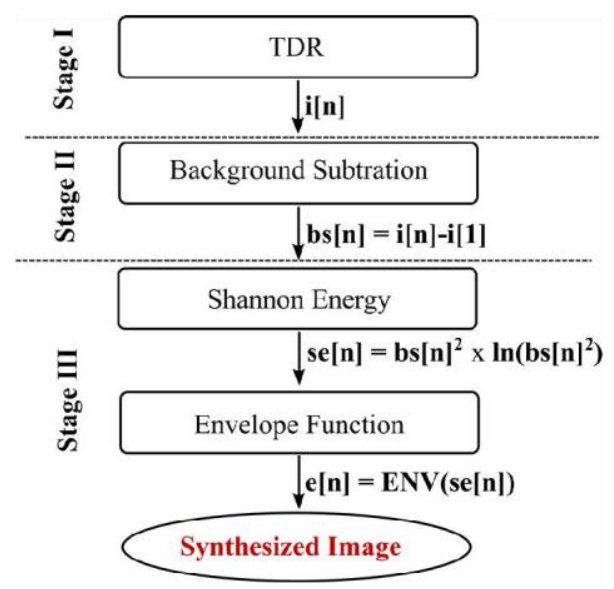

Fig. 8. Image Synthesized Stages.
Stage $\mathrm{I}$ is the matrix of TDR data (i [n]) that generates an image presented in Fig. 9 (a), (b) and (c), with (c) being the signal

Stage II, Fig. 9 (d), (e), and (f), is the background subtraction, which is the extraction of ambient noise caused by distorted waves. In this case, the signals from the first and last positions without the target (free space) are removed [8]. Stage II is expressed by equation (4).

$$
\mathrm{bs}[\mathrm{n}]=\mathrm{i}[\mathrm{n}]-\mathrm{i}[\mathrm{1}]
$$

Stage III has two stages, namely, Shannon energy and envelope. The Shannon energy (equation (5)) is based on the use of signal energy capable of finding the average spectrum and signal peaks [18], Fig. 9 (g), (h) and (i). The envelope (equation (6)), Fig. 9 (j), (k) and (1), extracts the local maximums, in this case, from the Shannon energy, by applying the derivative [8].

$$
\begin{gathered}
\operatorname{se}[\mathrm{n}]=\mathrm{bs}[\mathrm{n}]^{2} \times \ln \left(\mathrm{bs}[\mathrm{n}]^{2}\right) \\
\mathrm{e}[\mathrm{n}]=\operatorname{env}(\mathrm{e}[\mathrm{n}])
\end{gathered}
$$

In Fig. 9 (c), (f), (i) and (1) the signals generated at each processing step are shown and it is possible to observe that the signals of the model without tumor are smaller, this is due to $\varepsilon$ of the brain is much smaller than the 74 of the tumor and because the electric fields are more dispersed [12], therefore, having less intensity [17].

Fig. 9 (a) illustrates the image without tumor and Fig. 9 (b) with a tumor. At this first moment, it is not possible to notice any difference between the two images.

Fig. 9 (d) and (e), represent the image without and with a tumor, respectively, being possible to differentiate them already. There is a greater intensity in the central part of the image shown in Fig. 9 (e).

In Fig. 9 (g) and (h) the images without and with tumors, respectively, are shown. With each progression of the processing stage, the tumor appears more clearly, as can be seen in Fig. 9 (h), which already has more intense oval shapes near the front of the brain, where the tumor is located.

The last stage of signal processing is shown in Fig. 9 (j) and (k), where (j) is the image without a tumor and (k) is the image with a tumor. At this stage, the tumor is seen more clearly than in the previous stages. In Fig. $9(\mathrm{k})$ it is possible to detect the tumor that presents with intensity in the frontal part of the brain. 

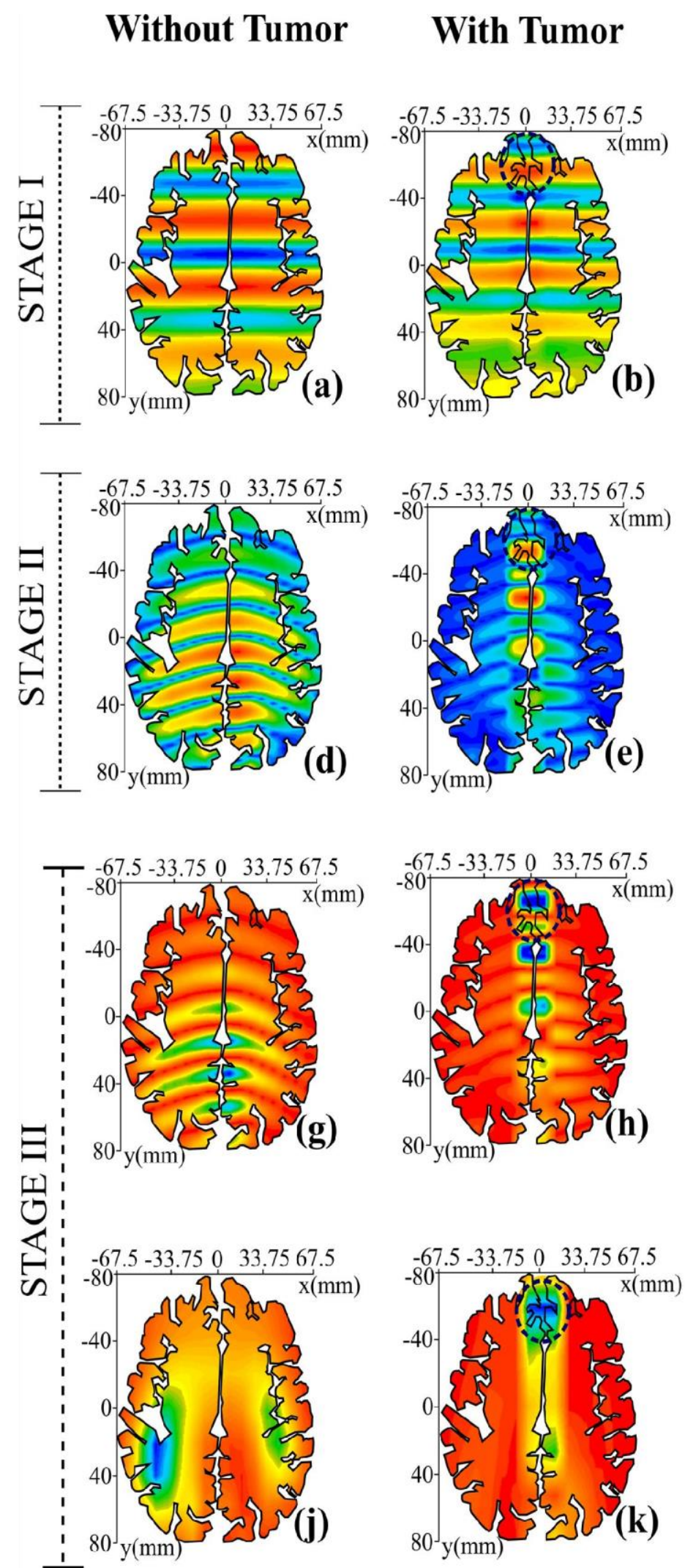

Fig. 9. Images and signs with and without tumor. TDR: (a) image without tumor, (b) image with tumor, (c) signal image with and without tumor;

Background subtraction: (d) image without tumor, (e) image with tumor, (f) signal with and without tumor; Shannon's energy: (g) image without tumor, (h) image with tumor, (i) signal with and without tumor; Envelope: (j) image without tumor, (k) image with tumor, (l) sign with and without tumor. 


\section{CONCLUSION}

The goals of increasing the gain, decreasing the SLL and squint of AVA were achieved with the antennas CNG9-FSEAVA, CNG18-FSE-AVA, and CNG27-FSE-

AVA leaving the radiation more stable and minimizing external interference, which is desirable in antennas used in UWB systems. Therefore, the proposed antennas are suitable for UWB systems. Besides the achievement of the objectives, it was also possible to conclude that the notched area of the lateral cavities in the AVA has different behavior in relation to frequency.

Regarding the objective of using the antenna to generate medical images, the work was also successful, since the CNG27-FSE-AVA was able to detect a tumor through simulations using signal processing. However, to confirm the effectiveness of this antenna to assist in medical diagnostics, it is necessary to further research by carrying out other experiments, such as measurements on realistic phantoms.

\section{ACKNOWLEDGMENT}

We acknowledge the IFSP Pro-rectory of Research and Direction of the Cubatão campus for promoting this research through the PIBIFSP-CBT ${ }^{\circ} 011 / 2019$.

\section{REFERENCES}

[1] C. A. Balanis, "Antenna theory: analysis and design". New Jersey, USA: John Wiley\& Sons, 2006. W.-K. Chen, Linear Networks and Systems, Belmont, CA: Wadsworth, 1993, pp. 123-135.

[2] I. T. Nassar, and T. M. Weller, "A novel method for improving antipodal Vivaldi antenna performance". IEEE Trans. Antennas Propag., vol. 63, no. 7, pp. 3321-3324, Jul. 2015.

[3] J. Bai, S. Shi, and D. W. Prather, "Modified compact antipodal Vivald antenna for 4-50-GHz UWB application". IEEE Transactions on Microwave Theory and Techniques, vol. 59, no.4, pp. 1051-1057, 2011.

[4] P. Fei, Y.C. Jiao, W. Hu, and F.S. Zhang, "A miniaturized antipodal Vivaldi antenna with improved radiation characteristics", IEEE Antennas Wireless Propag. Lett. Vol. 10, pp. 127-130, 2011.

[5] Y. Yang, Y. Wang, and A. E. Fathy, "Design of compact Vivald antenna arrays for UWB see through wall applications," Prog. Electromag. Research., vol. 82, pp. 401-418, 2008.

[6] A. M. De Oliveira, M.B. Perotoni, S.T. Kofuji, and J.F. Justo. "A palm tree antipodal Vivaldi antenna with exponential slot edge for improved radiation pattern". IEEE Antennas Wireless Propagation Lett. vol. 14, pp. 1334-1337, 2015.

[7] J. Bourqui, M. Okoniewski, and E. C. Fear, "Balanced antipodal Vivaldi antenna with dielectric director for near-field microwave imaging," IEEE Trans. Anten. Propag., vol. 58, no. 7, pp. 2318- 2326, Jul. 2010.

[8] A. M. De Oliveira, J. F. Justo, M. B. Perotoni, et al. "A high directive Koch fractal Vivaldi antenna design for medical near-field microwave imaging application". Microw. Opt. Technol. Lett. vol. 59, no. 2, pp 337-346. Feb. 2017

[9] S. Zhu, H. Liu, P. Wen, and Z. Chen. "A compact gain-enhanced Vivaldi antenna array with suppressed mutual coupling for $5 \mathrm{G} \mathrm{mm}$ Wave application". IEEE Antennas and Wireless Propagation Letters, v. 17 , no. 5, pp. 776-779, 2018

[10] A. M. De Oliveira, J. F. Justo, A. J. R. Serres, M. R. Manhani, R. H. C. Maniçoba, M. B. Perotoni, and H. Baudrand. "Ultra- directive palm tree Vivaldi antenna with 3D substrate lens for $\mu$ - biological near- field microwave reduction applications". Microwave and Optical Technology Letters. vol. 61, no. 3, pp. 713-719, 2019.
[11] L. Sha, E. R. Ward, and B. Stroy. "A review of dielectric properties of normal and malignant breast tissue." Proceedings IEEE Southeast. Conf. 2002 (Cat. No. 02CH37283). IEEE, 2002.

[12] A. Zamani, S. A. Rezaeieh, and A. M. Abbosh. "Lung cancer detection using frequency-domain microwave imaging". Electronics Letters, vol. 51, no. 10, pp. 740-741, 2015.

[13] B. J. Mohammed, A. M. Abbosh, S. Mustafa, D. Ireland, "Microwave system for head imaging," IEEE Trans Instrumentation and Measurement, vol. 63, pp. 117-123, Jan., 2014

[14] D. H. Werner, and S. Ganguly. "An Overview' of Fractal Antenna Engineering Research". IEEE Antennas and propagation Magazine, vol. 45, no. 1, pp. 38-57, 2003.

[15] Y. K. Choukiker, S. K. Sharma, and S. K. Behera, "Hybrid fractal shape planar monopole antenna covering multiband wireless communications with MIMO implementation for handheld mobile devices". IEEE Transactions on Antennas and Propagation, vol. 62, no. 3, pp. 1483-1488, 2013.

[16] K. M. Chew, R. Sudirman, N. H. Mahmood, N. Seman, and C. Y. Yong, "Human Brain Microwave Imaging Signal Processing: Frequency Domain (S-parameters) to Time Domain Conversion," Engineering, vol. 5,p.31,2013

[17] A. Zamani, A. M. Abbosh, and A. T. Mobashsher, "Fast frequency based multistatic microwave imaging algorithm with application to brain injury detection," IEEE Trans. Microw. Theory Techn., vol. 64, no. 2, pp. 653-662, Feb. 2016.

[18] H. Beyramienanlou, and N. Lotfivand. "Shannon's energy based algorithm in ECG signal processing.", Computational and mathematical methods in medicine, 2017. 